\title{
Social Media Used in Higher Education: A Literature Review of Theoretical Models Waleed Mugahed Al-Rahmi ${ }^{1 *}$, Norma Alias ${ }^{2}$, Mohd Shahizan ${ }^{3}$
}

\begin{abstract}
This research provides a literature review related with social media used for collaborative learning and engagement in turn, to affect students' academic performance in higher education. Therefore, the main objective of this research is to review models on social media use for active collaborative learning and engagement by interactive and perceptual factors in turn affecting the learning performance of research students. Therefore, this study conducted on two theories constructivism theory and Technology Acceptance Model (TAM). This paper conducted an analysis of studies dedicated to social media use for collaborative learning and engagement based on previous research problems of models, and the theories. According to the literature review and discussion in this research, we noted the full satisfaction of students was through the use of social media for active collaborative learning and engagement to positively affect their learning performance.
\end{abstract}

Keywords - Social Media, Collaborative Learning, Students' Academic Performance, Theoretical Model

\section{INTRODUCTION}

$\mathbf{M}$ ALAYSIA like many other countries has been hit by the social media phenomenon. Statistics reveal that Malaysia is among the top five countries in terms of number of Facebook accounts created [1,2]. Social media is widely considered as facilitating active collaborative learning among research students. However, there is a lack of research on this topic in Malaysian higher education. Thus, the present research attempted to minimize the literature gap by examining the use of social media for active collaborative learning and engagement to affect learning performance of research students. The research model was developed on the basis of the constructivism theory and technology acceptance model (TAM). Based on the constructivism theory and technology acceptance model (TAM), this research provided insight about interactive and perceptual factors of social media use. The interactive factors included interactivity with group member or peers, interactivity with supervisor or lecturers, active collaborative learning and engagement. Perceptual factors included perceived ease of use, perceived usefulness, social media use and satisfaction of research students. Therefore, both interactive and perceptual factors affect learning performance of research students in Malaysian higher education. Active collaborative learning can occur on social media, as they can be used to help individuals work together to complete a collective objective [3]. In addition to this, social media use facilitates positive relationship between the learning performance and satisfaction of research students [4].

1\& 2 Ibnu Sina Institute for Scientific and Industrial Research (ISI-SIR), Faculty of Science, Universiti Teknologi Malaysia, 81310, UTM Skudai, Johor, Malaysia.

${ }^{3}$ Department of Information System, faculty of computing, Universiti Teknologi Malaysia, 81310, UTM Skudai, Johor, Malaysia.

* Corresponding author Waleed Al-Rahmi: waleed.alrahmi@yahoo.com
Furthermore, [5] reported a positive relationship between students learning performance and Facebook usage. [6] expressed active collaborative learning as the continuum by students for interactive and engagement to exchange ideas and viewpoints through social media [2] for example Facebook. The overall idea of communication is a system that allows individuals to take advantage of technology to interact, collaborate and communicate on content, opinions, encounters, experience, and technologies within a group by active collaborative learning and engagement [7].

Social media ease of use and usefulness helps students to become more active, create understanding and discussion among peers, supervisors, instructor and experts, the receipt of expert guidance, and problem fixing abilities [8]. Perceived ease of use and perceived usefulness were statistically significant predictors for satisfaction. Statistically, satisfaction is significantly higher for users who have more friends and who interact with more students compared to those who have fewer friends and less interactivity [9].

Researchers have addressed various issues and phenomena using social media network at various academic and social levels. Extant literature on social media is of opinion that various helpful methods can be applied in higher education sector. However, this research aims to review a model on social media use for active collaborative learning and engagement by interactive and perceptual factors in turn affecting the learning performance of research students. In this research, we discussion of the contents of the proposed model for using social media for active collaborative learning to influence learning performance of research students in Malaysian higher learning institution is presented. The contents of the model include interaction with research group member or peers, interaction with supervisors or lecturers, engagement, perceived ease of use and perceived usefulness via active collaborative learning with social media use to affect satisfaction and learning performance of research students.

\section{PROBLEM BACKGROUND}

Students seldom use social media for educational purposes [10]. Furthermore, students use social media for socializing activities and not for interactivity to active collaborative learning, engagement and academic purpose [4]. According to [11], a research model of antecedents and consequences of social media was used but results indicated a higher perceived risk of using social media to waste time and reduce motivation to learn. It is likely that most Malaysian higher education students use social media and spend many hours checking social media, and that there is an adverse aspect to research student's utilization of social media. There is a 
growing concern that the use of extensive social media can lead to loss of motivation. [12] Described that motivation may increase the inner wish of the particular student to do well in learning performance. Accordingly, [13] indicated that collaborative class activities can be accompanied by individual projects to enhance student learning. Students' have a strong desire to have active collaborative learning and learning with technology, and for that reason their novelty effects may be misleading in the belief that social media supports active collaborative learning [14]. The effects of using social media based active collaborative learning were investigated and it was found that social media could increase learning achievements in active collaborative learning environments. Consequently, researchers should track and analyze the interaction pattern that occurs during active collaborative learning [15].

\section{THEORETICAL MODEL}

Social media as an information facility in institutions of learning provides a platform for efficient teaching and learning processes. However, to promote the proper use of social media in educational subsector, policies that guide and enable users should be implemented as suggested in existing literatures. Currently, the global information revolution is growing rapidly. Government and educational institution managers should be ready to provide secure online services to their youth especially those in institutions of higher education.

\section{A. Research Theories}

Students unable to find a cognitive balance and who have tried to become accustomed to obtaining equilibrium cognition and supported the learners to build the knowledge as the theory of social constructivist of $[5,16]$ that see in social media network interactive and the perspective of allotment of knowledge and information or discuss with others. Thus this study use Constructivism [5] in support of the basic idea that learning is an active, constructive process. This study also uses Technology Acceptance Model (TAM) as introduced by [17]. This model focuses on investigating the factors that influence individuals' social media using a specific innovation or service [17]. Several studies found that perceived ease of use and perceived usefulness have a significant role in influencing satisfaction and individuals' intention in using a new technology [18-23].

\section{B. Social Constructivism}

The foundation of social constructivism in the context of education was built on Vygotsky's work. He emphasized the role of others, or the social context, in learning and as a result, educators were urged to restudy the level to which learning is a process confined to the individual [16]. Also [16] contended that the path between objects and thought is mediated by other individuals via language signs and symbols [24]. Human history is built on man's increasing domination over nature via the invention of tools and the perfection of technology, and on the other hand, man gradually acquires self-control through invention of cultural sign methods [24]. Additionally, [16] over-emphasized culture and society by contending that all higher mental functions originate from society and are integrated in socio-cultural environment. [16] Explained that learning is best understood in relation to other individuals and this ongoing interaction between individuals and others is referred to as the zone of proximal development (ZPD). It is defined as the intellectual potential of the individual when assisted by a knowledgeable adult or a more knowledgeable child [16]. In other words, the individual is regulated in the learning process by a capable peer or by the teacher.

\section{Active Collaborative Learning Theory}

Cooperative learning takes place in groups, and it is where individuals work together to accomplish their shared learning goals [25]. The desired outcomes are seen as beneficial to the individuals themselves and also to their group members [26]. Cooperative learning is derived from three general theoretical perspectives: social interdependence, cognitive-development and behavioral learning theories. Active collaborative learning is comprised of five basic elements: positive interdependence, individual accountability, primitive interaction, interpersonal and small group skills, and group processing [27]. Positive interdependence is the most important element; it "exists when group members perceive that they are linked with each other in a way that one cannot succeed unless everyone succeeds If one fails everyone fails" [25].

\section{Technology Acceptance Model (TAM) Theory}

Several researchers in the field of information systems have reported the under-utilization of IT in several organizations. As a consequence, many technology acceptance theories and models have been proposed and used to study such acceptance including the theory of Reasoned Action proposed by [28], the Technology Acceptance Model proposed by [29], and extended TAM proposed by [30], and the Unified Theory of Acceptance and Use of Technology (UTAUT) proposed by [31].

\section{E. Theory of Reasoned Action}

The theoretical model of reasoned action (TRA) in the field of information system technology acceptance proposes that perceived usefulness and perceived ease of use describe the intention of the individual to use a system in this relationship; intention mediates the actual system use. Moreover, perceived usefulness is considered to be directly influenced by perceived ease of use. Both student and research groups have summarized TAM by deleting the attitude construct adopted from the TRA to suit the current situations [31]. See figure 1. 


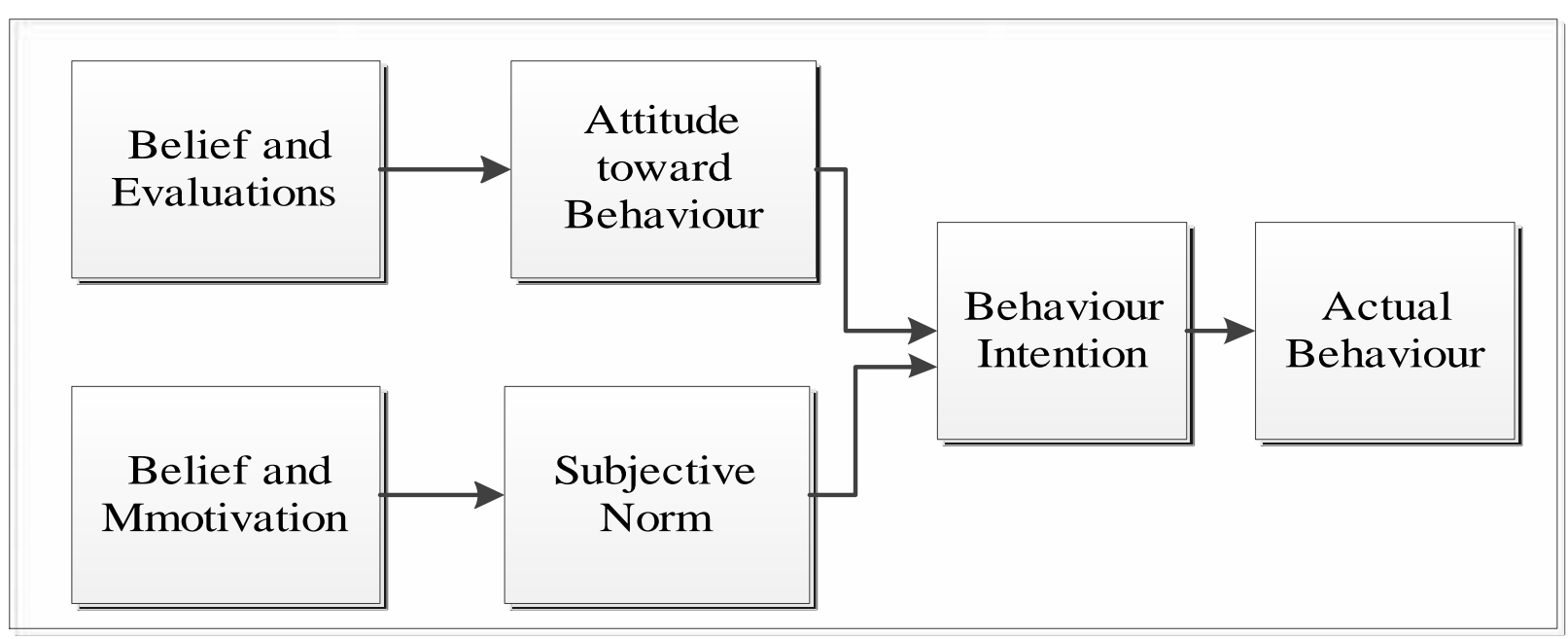

Fig 1: Theory of Reasoned Action [31]

\section{RESEARCH MODEL}

This study attempts proposes a framework for the impact of social media use on collaborative learning among researchers at five research universities in Malaysian higher education, based on the constructivism theory (See Figures 2). From Figure.2, the model identifies instruments by which using social media for active collaborative learning and engagement influence learning performance of research students to use social media which in turn also affects the researchers' satisfaction. Meanwhile, social media increases the quality of interaction within the class both in terms of student interaction with peers and researchers and also teachers or supervisors [32]. Interaction created is a critical aspect in the training process. It encourages students to have active collaborative learning [33], and also creates a sustained behaviour participation in mastering activities in the engagement [34]. According to [35, 36, 23], students' learning performance was measured using the following three factors: interaction with peers (research group member), interaction with teacher or supervisors and engagement with active collaborative learning. In addition, [37] measured students' learning performance using active collaborative learning and student interaction. [38, 39], found factors of usefulness and ease of use, First, usefulness of social media is defined as the degree to which an individual believes that the use of social media would enhance his/her communication, collaboration and information exchange. Second, ease of use is defined as the degree to which an individual believes that using Facebook would be free of physical and mental effort. The above mentioned factors have an impact on active collaborative learning directly and also on the social media use. Positive attitude, perceived ease of use and perceived usefulness of use social media for active collaborative learning and engagement and the existence of these components are instrumental on active collaborative learning influence learning performance of research students $[29,2$, $20,22]$.

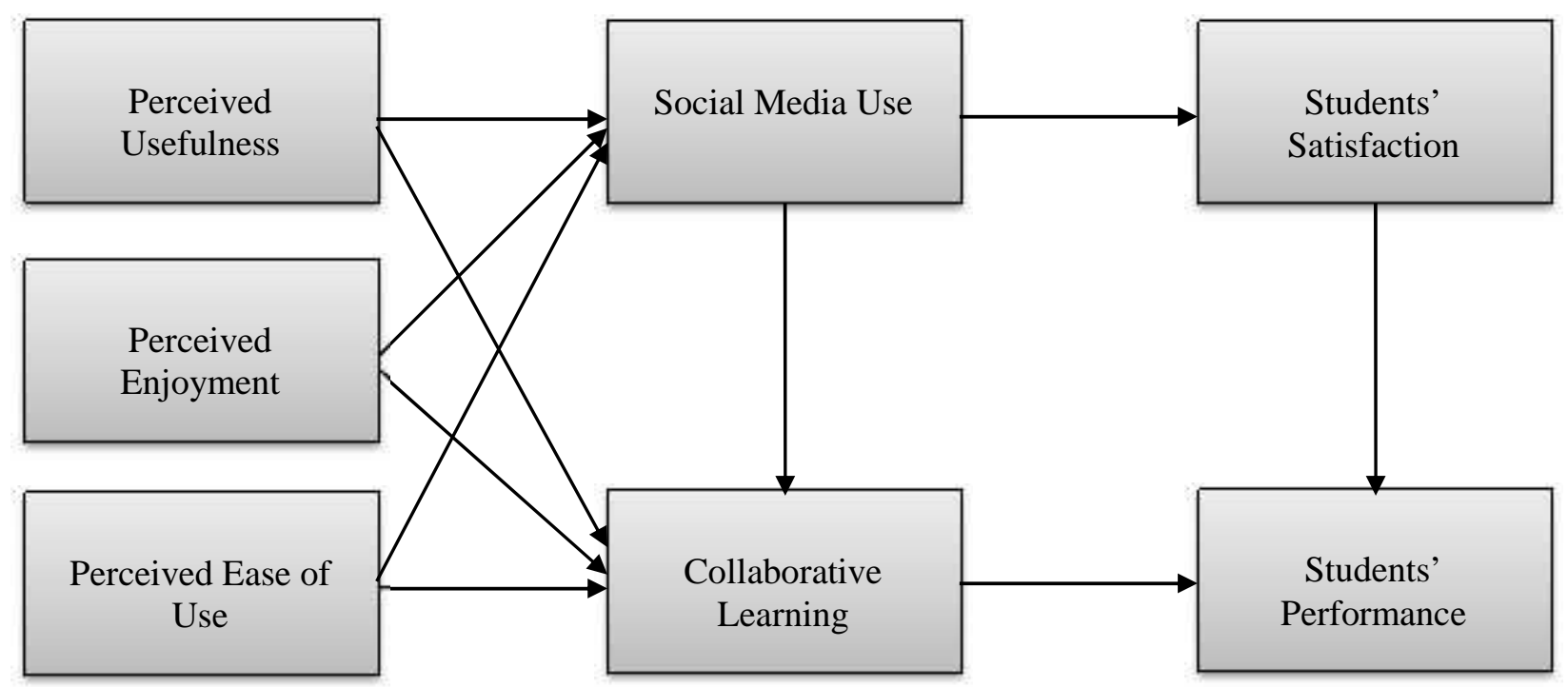

Fig 2: The research model with hypotheses [40] 


\section{DISCUSSION}

In this research the social media use for active collaborative learning is the key factor in building technology utilization models [17, 31]. More specifically, among others, [41] found that perceptions of usefulness and ease of use increases with the social media use. The TAM approach is characterized with flexibility as it extends to include other variables that assist in explaining acceptance of technology [42]. The relationship between perceived ease of use, perceived usefulness and social media use is justified by many studies in literature [17]. Also, the relationship between perceived usefulness and social media use in the case of TAM is supported by statistical results by studies. The inclusive nature of the perceptions of both usefulness and ease of use and of the interactive aspects of the social media network in light of knowledge sharing and information exchange active collaborative learning and engagement may influence the satisfaction level of users [43]. However, social media tool acceptance depends on ease of use and usefulness in that both are required criteria to expand the use of the tool within a specific social media circle for active collaborative learning for positive outcomes. As for social communication behaviour online, a more positive attitude towards the use of online communication tools is aligned to higher behavioural intention to its use [44].

The consumer perceives the machine to become an ideal way of carrying out the duties [45, 17, 23]. It does appear that there is an enhanced trend among users to embrace the above mentioned social networking sites particularly at college level. It appears to possess transformed communication designs even at local level. [2, 21, 40] stated that social networking can offer new methods for individuals to interact within the research group member and class. The popularity of utilizing social networking among college students appears to increase on a daily basis and many of them depend on its usage for interaction and communication with supervisors. Researchers' satisfaction with active collaborative learning is definitely a result of the collaboration process and could be referred to mean the degree those students and researchers feel an optimistic connection to their own active collaborative learning encounters $[2,23,40]$. Nonetheless, country's profile and accessibility to the infrastructure play a vital role in the enhanced usage. Added to this, learner's satisfaction with active collaborative learning refers to the level to which a

\section{REFERENCES}

[1] Ainin, S., Naqshbandi, M. M., Mogavvemi, S., and Jaafar, N. I. (2015). Facebook usage, socialization and academic performance. Computers \& Education. 83 (2015) 64-73.

[2] Al-Rahmi, M.A., Mohd, S.O., and Lizawati, M. Y., (2015). The Role of Using Social Media for Collaborative Learning to Improve Academic Performance of Students and Researchers in Malaysian Higher Education, The International Review of Research in Open and Distributed Learning, Vol. 16, No. 4, pp.1-27.

[3] Cheung , R and Voge, D.(2013).Predicting user acceptance of collaborative technologies: An extension of the technology acceptance model for e-learning. Computers \& Education 63 (2013) 160-175.

[4] Cao, Y., and Hong, P. (2011). Antecedents and consequences of social media utilization in college teaching: a proposed model with mixedmethods investigation, 19(4), 297-306. learner positively perceives his active collaborative learning experiences [36, 40, 46]. In the context of the educational arena, the social networking sites effectiveness is reported to enhance active collaborative learning outcomes. Specifically, $[47,2]$ recommend such learning approach by discussing its potential. Moreover, $[48,23,2]$ report that networking in the educational realm has the potential to enhance the learning performance of students and that social networking enriches the learning environment. This can be done by highlighting students' needs and formative assessment through the creation of classroom community, facilitation of students' engagement, increased student achievement, information management and sharing of knowledge among students.

\section{CONCLUSION AND FUTURE WORK}

This research proposed a systematic literature review of theoretical models and frameworks which indicates the perception of students in regard to the use of social media and how it influences the learning performance of research students. It can be observed that the use of social media influences the learning performance of research students. The variables observed on using social media for active collaborative learning and engagement, In this research the relevant interactive and perceptual factors include interaction with research group member or peers, interaction with supervisors or lecturers, active collaborative learning, engagement, perceived ease of use, perceived usefulness and social media use as the dependent variables that influence students' satisfaction and learning performance of research students. The active collaborative learning and engagement with social media use as the mediator is described. Therefore, we recommend more studies related with constructivism theory and TAM Model to measure students' academic performance in higher education.

\section{ACKNOWLEDGMENTS}

We would like to thank the Research Management Centre (RMC) at Universiti Teknologi Malaysia (UTM) for funding this project under grant number PY/2015/05399 / R.J130000.7826.4F795. We also would like to thank the Ibnu Sina Institute for Scientific and Industrial Research (ISI-SIR), Faculty of Science, Universiti Teknologi Malaysia and Hudaidah University - Yemen for supporting this research.

[5] G. O. Young, "Synthetic structure of industrial plastics (Book style with paper title and editor)," in Plastics, 2nd ed. vol. 3, J. Peters, Ed. New York: McGraw-Hill, 1964, pp. 15-64.

[6] Alloway, T. and Alloway, R. (2012). The impact of engagement with social networking sites (SNSs) on cognitive skills. Computers in Human Behavior, 28(5), 1748-1754.

[7] Ala-mutka, K., and Punie, Y. (2010).Learning 2 . 0 The Impact of Social Media on Learning in Europe. Policy brief. JRC Scientific and Technical Report. EUR JRC56958 EN.

[8] Hamid, S., Waycott, J., and Kurnia, S. (2011). Appropriating Online Social Networking (OSN) Activities for Higher Education: Two Malaysian Cases. 526-538

[9] Sibona.C., and Choi,J.(2012). Factors Affecting End-User Satisfaction on Facebook. Proceedings of the Sixth International AAAI Conference on Weblogs and Social Media.2012.

[10] Argan, M. (2010). Using Online Social Networking : Students Purposes of Facebook Usage at the University of Turkey, (September 2010). 
[11] Cao, Y., Ajjan, H., and Hong, P. (2013). Using social media applications for educational outcomes in college teaching: A structura equation analysis. British Journal of Educational Technology, 44(4), 581-593.

[12] Rouis, S., Limayem, M., and Salehi-sangari, E. (2011). Impact of Facebook Usage on Students' Academic Achievement: Roles of Self-Regulation and Trust. 9(25), 961-994.

[13] Arthurs, L., and Templeton, A. (2009). Coupled collaborative in-class activities and individual follow-up homework promote interactive engagement and improve student learning outcomes in a college-level Environmental Geology course. Journal of Geoscience Education, 57(5), 356-371.

[14] Mustapha, R. (2010). Collaborative Strategic Reading with University EFL Learners.

[15] Su, A., Yang, S., Hwang, W., and Zhang, J. (2010). A Web 2.0-based collaborative annotation system for enhancing knowledge sharing in collaborative learning environments. Computers \& Education, 55(2), $752-766$.

[16] Vygotsky, L. S. (1978). Mind in society: The development of higher psychological processes. Cambridge, MA: Harvard University Press.

[17] Davis, F.D., (1989). Perceived usefulness, perceived ease of use and user acceptance of information technology. MIS Quarterly 13, 319-340.

[18] Karaali, D., Gumussoy, C. A., and Calisir, F. (2011). Factors affecting the intention to use a web-based learning system among blue-collar workers in the automotive industry. Computers in Human Behavior. 27(1): 343-354.

[19] Lee, Y., Hsieh, Y., and Ma C. (2010). A model of organizational employees' e-learning systems acceptance. Knowledge-Based Systems. 24(3): 355-366.

[20] Al-rahmi, W. M. Othman, M.S. Yusof, L.M and Musa. M.A. (2015). Using Social Media as a Tool for Improving Academic Performance through Collaborative Learning in Malaysian Higher Education. Review of European Studies, 7(3), p265.

[21] Al-rahmi, W. M., Othman, M. S., \& Yusuf, L. M. (2015). Social Media for Collaborative Learning and Engagement: Adoption Framework in Higher Education Institutions in Malaysia. Mediterranean Journal of Social Sciences, 6(3 S1), 246.

[22] Al-rahmi, W. M., Othman, M. S., \& Yusuf, L. M. (2015). The Effect of Social Media on Researchers' Academic Performance through Collaborative Learning in Malaysian Higher Education. Mediterranean Journal of Social Sciences, Vol 6 No 4(S1), 193.

[23] Al-Rahmi ,W, Othman ,M and Musa, M. (2014). The Improvement of Students' Academic Performance by Using Social Media through Collaborative Learning in Malaysian Higher Education. Asian Social Science; Vol. 10, No. 8; 2014.

[24] Veer, R. and Valsiner, J. (1993). Understanding Vygotsky. Oxford, UK: Blackwell.

[25] Jonassen, H., Howland, L., Moore, L., and Marra, M. (2003). Learning to solve problems with technology: A constructivist perspective. Upper Saddle Rover, NJ: Merrill Prentice Hall.

[26] Jonassen, H., Howland, L., Moore, L., and Marra, M. (2003). Learning to solve problems with technology: A constructivist perspective. Upper Saddle Rover, NJ: Merrill Prentice Hall.

[27] Johnson and Christensen (2010).educational research: quantitative, qualitative, and mixed approaches .university of south Alabama, SAGE Publications.

[28] Fishbein, M., and Ajzen, I. (1975).Belief, Attitude, Intention and Behavior: An Introduction to Theory and Research, Addison-Wesley, Reading, MA, 1975.

[29] Brooks, J.G. and M.G. Brooks. (1993).In search of understanding: the case for constructivist classrooms. Alexandria, VA: Association for Supervision and Curriculum Development.
[30] Davis, F.D., (1993). User acceptance of information technology: system characteristics, user perceptions, and behavioral impacts. International Journal of Man Machine Studies 38, pp. 475-487.

[31] Venkatesh, V., Morris, G., Davis, B., and Davis, D. (2003). User acceptance of information technology: Toward a unified view. MIS Quarterly, 27(3), 425-478.

[32] Banks. (2006). Reflections on the use of ARS with small groups. In D A. Banks (Ed.), Audience response systems in higher education (pp. 373-386). Hershey, PA: Information Science Publishing.

[33] Guthrie, and Carlin (2004) .Waking the dead: using interactive technology to engage passive listeners in the classroom. In Proceedings of the AMCIS, paper 358. New York: August.

[34] Carnaghan and Webb (2007). Investigating the effects of group response systems in student satisfaction, learning, and engagement in accounting education. Issues in Accounting Education, 22(3), 391-409.

[35] Arcas, B L., Buil, I., Hernández-Ortega, B., and Sese, F. J. (2013). Using clickers in class. The role of interactivity, active collaborative learning and engagement in learning performance. Computers \& Education, 62, 102-110.

[36] Al-Rahmi, W. and Othman, M. (2013).The Impact of Social Media use on Academic Performance among university students: A Pilot Study. Journal of information systems research and innovation 2013.

[37] Alexander, R, (2009). An exploration of the relationship between student engagement and academic performance of undergraduate students in education.

[38] Sanchez, Cortijo and Javed (2014).Students' perceptions of Facebook for academic purposes. Computers \& Education journal.

[39] Mazman, S. G., and Usluel, Y. K. (2010). Modeling educational use of Facebook. Computers \& Education, 55(2), 444-453. P10.

[40] Al-Rahmi, W.M., and Zeki, M. A., (2016). A Model of Using Social Media for Collaborative Learning to enhance learners' Performance on learning, Journal of King Saud University - Computer and Information Sciences, http://dx.doi.org/10.1016/j.jksuci.2016.09.002.

[41] Davis, F.D., (1993). User acceptance of information technology: system characteristics, user perceptions, and behavioral impacts. International Journal of Man Machine Studies 38, pp. 475-487.

[42] Venkatesh, V., and Davis, F. D. (2000).A Theoretical Extension of the Technology Acceptance Model: Four Longitudinal Field Studies. Management Science (46:2), 2000, pp. 186-204.

[43] Wixom, H., and Todd,A. (2005). A theoretical integration of user satisfaction and technology acceptance. Information Systems Research, 16(1), 85-102.

[44] Chang , H. H. and Wang, I. C. (2008).An investigation of user communication behavior in computer mediated environment Computers in Human Behavior, vol. 24, no. 5, pp. 2336-2356, 2008

[45] Mazman, S. G., and Usluel, Y. K. (2010). Modeling educational use of Facebook. Computers \& Education, 55(2), 444-453. P10.

[46] Dewiyanti, S., Brand-Gruwel, S., Jochems, W., and Broers, N. J. (2007). Students' experiences with collaborative learning in asynchronous computer-supported collaborative learning environments. Computers in Human Behavior, 23, 496-514

[47] Arnold, N. and Paulus, T. (2010). Using a social networking site for experiential learning: Appropriating, lurking, modeling and community building. Internet and Higher Education, 13, 188-196.

[48] Karpinski, C., Kirschner, P., Ozer, I., Mellott, J., and Ochwo, P. (2013) An exploration of social networking site use, multitasking, and academic performance among United States and European university students. Computers in Human Behavior, 29(3), 1182-1192. 